\title{
Sol-gel synthesis of hybrid materials
}

\author{
J LIVAGE \\ Chimie de la Matière Condensée, Université Pierre et Marie Curie, 4 place Jussieu, 75232 Paris, France
}

\begin{abstract}
Sol-gel chemistry allows the synthesis of hybrid organic-inorganic materials. Organic molecules can be used as complexing ligands to provide a chemical control over hydrolysis and condensation reactions, leading to the formation of stable suspensions of nanoparticles. They can also be trapped within the sol-gel matrix in order to provide some optical properties such as photochromism. When chemically bound to the oxide network via Si-C bonds they lead to hybrid nanocomposites that offer new possibilities in the field of materials science. Even biospecies, such as enzymes or antibodies, can be trapped within sol-gel matrices in order to make bio-sensors or bio-catalysts.
\end{abstract}

Keywords. Sol-gel; hybrids; biosensors.

\section{Introduction}

The synthesis of glasses and ceramics via 'chimie douce' has been widely developed during the last two decades. These syntheses usually involve wet chemistry reactions, and are based on the inorganic polymerization of molecular precursors, such as metal alkoxides in the case of sol-gel chemistry. These precursors are mixed at the molecular level and multicomponent materials may be formed at much lower temperatures. The sol-gel route allows the powderless processing of glasses and ceramics. Thin films or fibres can be produced directly from the solution by such techniques as dip-coating, spin-coating, and spin-drawing. However, the main advantage of sol-gel chemistry is to provide mild conditions so that organic species can be mixed with the inorganic precursors, leading to the formation of hybrid organic-inorganic systems.

A wide range of novel hybrid materials have been synthesized wherein organic or biomolecules are mixed with metal oxides at a molecular level. This paper reviews some of the main results that we have obtained in our laboratory during the past few years.

\section{Synthesis of fine particles via chemically controlled condensation}

Sol-gel chemistry is based on the hydrolysis and condensation of alkoxides, $\mathrm{M}(\mathrm{OR})_{2}$, where $\mathrm{M}^{\mathbf{}}$ is a metal, and ' $R$ ' an alkyl group ( $R=M e, E t \ldots)$.

In the case of silicon, $\mathrm{Si}^{\mathrm{IV}}$, hydrolysis leads to the formation of $\mathrm{M}-\mathrm{OH}$ groups.

$$
>\mathrm{Si}-\mathrm{OR}+\mathrm{H}_{2} \mathrm{O} \Rightarrow>\mathrm{Si}-\mathrm{OH}+\mathrm{ROH} \text {. }
$$

The condensation of two $\mathrm{M}-\mathrm{OH}$ groups via oxolation leads to the formation of oxo bridges, $\mathrm{M}-\mathrm{O}-\mathrm{M}$ represented by the following:

$$
>\mathrm{Si}-\mathrm{OH}+\mathrm{HO}-\mathrm{Si}<\Rightarrow>\mathrm{Si}-\mathrm{O}-\mathrm{Si}<+\mathrm{H}_{2} \mathrm{O} \text {. }
$$

The overall generalized reaction can be written as:

$$
\mathrm{Si}(\mathrm{OR})_{4}+2 \mathrm{H}_{2} \mathrm{O} \Rightarrow \mathrm{SiO}_{2}+4 \mathrm{ROH} \text {. }
$$

Alkoxides are not miscible with water so that a common solvent, usually the parent alcohol $\mathrm{ROH}$, has to be used. The oxide network progressively grows from the solution, leading to the formation of oligomers, oxopolymers, colloids (sols or gels), and finally a solid phase. These reactions can be described as $S_{\mathrm{N}^{2}}$ nucleophilic substitutions and the chemical reactivity of metal alkoxides towards hydrolysis and condensation depends mainly on the ability of the metal ion to increase its coordination number (Livage et al 1988). Transition metal alkoxides are therefore highly reactive. For instance, addition of water to zirconium alkoxide, $\mathrm{Zr}\left(\mathrm{OPr}^{\mathrm{i}}\right)_{4}$, leads to the uncontrolled precipitation of polydispersed zirconia powders. This arises mainly from the tendency of $\mathrm{Zr}^{\mathrm{IV}}$ to increase its coordination number up to 7 or 8 , as in crystalline zirconia $\mathrm{ZrO}_{2}$.

Complexing organic ligands, such as acetylacetone ( $\mathrm{acacH}=\mathrm{CH}_{3}-\mathrm{CO}-\mathrm{CH}_{2}-\mathrm{CO}-\mathrm{CH}_{3}$ ), have to be added to the alkoxide solution, prior to its hydrolysis, in order to decrease its reactivity. A slightly exothermic reaction occurs as follows:

$$
\mathrm{Zr}\left(\mathrm{OPr}^{n}\right)_{4}+x \text { acacH } \Rightarrow \mathrm{Zr}\left(\mathrm{OPr}^{n}\right)_{3-x}(\mathrm{acac})_{\mathrm{r}}+x \mathrm{Pr}^{n} \mathrm{OH} .
$$

Acetylacetone actually behaves as a chelating ligand resulting in the formation of new molecular precursors. The $\mathrm{Zr}$-acac bond is stabilized by chelation, and $\beta$ diketonates are much more difficult to hydrolyze than 
alkoxy groups. They decrease the reactivity and functionality of the new molecular precursor, prevent further condensation, and lead to the formation of smaller zirconium-oxo species (Sanchez et al 1992).

The modified precursor, $\mathrm{Zr}\left(\mathrm{OPr}^{n}\right)_{3-x}(\mathrm{acac})_{x}$, can then be hydrolyzed by adding a given amount of water, $h=\left[\mathrm{H}_{2} \mathrm{O}\right] /[\mathrm{Zr}]$, to the solution. The hydrolysis of alkoxy ligands gives reactive $\mathrm{Zr}-\mathrm{OH}$ groups allowing condensation to proceed and larger species to grow. The size and composition of the resulting condensed species can then be chemically controlled with two parameters: the complexation ratio $x=[\mathrm{acac}] /[\mathrm{Zr}]$ and the hydrolysis ratio $h=\left[\mathrm{H}_{2} \mathrm{O}\right] /[\mathrm{Zr}]$ (figure 1).

A gelatinous precipitate of amorphous hydrous zirconia, $\mathrm{ZrO}_{2}, n \mathrm{H}_{2} \mathrm{O}$, is formed for low complexation ratio $(x \leq 0 \cdot 1)$, whereas solute molecular clusters are formed when a small amount of water $(h<1)$ is added. Amorphous colloidal particles are obtained when more water is added to the modified precursor solution. Their mean diameter, measured by light scattering, increases when $h$ increases and $x$ decreases, as shown in table 1 .

Crystalline zirconia cannot be obtained when hydrolysis is performed at room temperature. Two conditions are required for crystallization to occur: (i) the solution must be heated in order to favour ion diffusion and increase

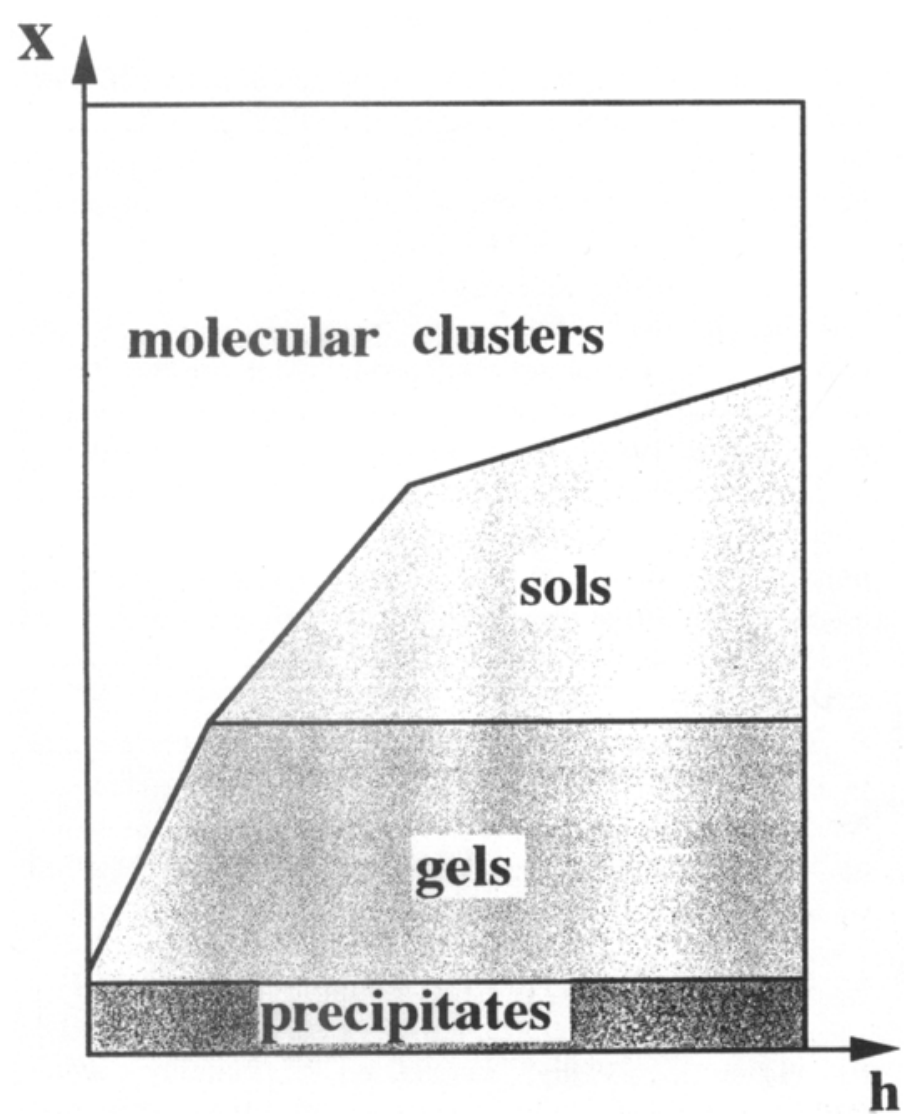

Figure 1. Nature of the condensed species formed via the hydrolysis and condensation of $\mathrm{Zr}\left(\mathrm{OPr}^{n}\right)_{3-x}(\mathrm{acac})_{x}$ precursors as a function of complexation ' $x$ ' and the hydrolysis ratio $h=\mathrm{H}_{2} \mathrm{O} / \mathrm{Zr}$. crystallization rates and (ii) complexing acac ligands have to be removed in order to allow more $\mathrm{Zr}-\mathrm{O}-\mathrm{Zr}$ bonds to be formed. These conditions are fulfilled when the solution of hydrolyzed precursors is refluxed with paratoluene sulfonic acid (PTSA). $\beta$-diketonate ligands become more labile in an acid medium and can be then released in the solution. Transparent sols are obtained that remain stable for several months. These sols are made up of monodisperse colloidal particles of tetragonal zirconia, with a mean hydrodynamic diameter in the 1-5 $\mathrm{nm}$ range (Chatry et al 1994). Similar experiments have been performed with titanium alkoxides (Blanchard et al 1995). These show that the surface of the colloidal oxide particles is covered by organic groups which prevent aggregation via steric hindrance effects (Scolan et al 1998).

These stable colloidal solutions of monodispersed oxide particles have been used for deposition of microporous zirconia membranes (Guizard et al 1994). A thin layer, about $0.2 \mu \mathrm{m}$ in thickness, made of nonaggregated nanosized particles is obtained after calcination at $500^{\circ} \mathrm{C}$. It is made up of very small grains of tetragonal zirconia. The pore size depends on the mean diameter of the closed packed spherical particles and very narrow pore size distributions are obtained in the nanometer range.

\section{Sol-gel optics in hybrid matrices}

One of the major advances in sol-gel processes, during the last few years, is undoubtedly the synthesis of hybrid organic-inorganic materials. The mild conditions associated with sol-gel chemistry provide a versatile access to such hybrids. The intimate mixing of molecular precursors in organic solvents allows organic and inorganic components to be associated at the molecular level (Sanchez and Ribot 1994).

Most hybrids are based on silica. This is mainly due to the fact that the covalent $\mathrm{Si}-\mathrm{C}$ bond remains stable against hydrolysis. The main application of these hybrid materials is for optical devices wherein organic dyes are trapped within the sol-gel matrices. In these nanocomposites, the mean size of organic and inorganic phases can be of the order of few nanometers. Therefore they are transparent and can be used for optical applications (Boilot et al 1996). Moreover, due to their improved mechanical properties, hybrid sol-gel matrices can be polished down to one nanometer in surface

Table 1. Mean diameter $(\AA)$ of zirconia colloids as a function of complexation ' $x$ ' and hydrolysis ' $h$ ': $\mathrm{Zr}\left(\mathrm{OPr}^{\prime \prime}\right)_{4}+$ $x$ acacH $+h \mathrm{H}_{2} \mathrm{O}$.

\begin{tabular}{rrrr}
\hline$h / x$ & $0 \cdot 3$ & 0.5 & 1 \\
\hline 2 & 20 & 30 & 30 \\
4 & 400 & 50 & 30 \\
10 & gel & 150 & 50 \\
\hline
\end{tabular}


roughness. Sol-gel optics takes advantage of the optical properties of organic dyes together with the hardness and optical transparency of silica.

Actually organic dyes are not just physically entrapped within the sol-gel matrix. Weak interactions between organic molecules and the silica network appear to play an important role in the optical properties of organic dyes. This is clearly demonstrated by the photochromic behaviour of spirooxazine in hybrid gels. Upon irradiation, colourless spirooxazine undergo an heterolytic $\mathrm{C}-\mathrm{O}$ ring cleavage giving coloured forms of merocyanines. This coloured form is more stable in an hydrophylic medium, whereas the colourless form prefers hydrophobic environments. The optical response of spirooxazine dyes thus depends on the chemical nature of the surrounding matrix. Two types of photochromic behaviour have actually been observed (Levy 1997): (i) direct photochromism is observed when spiropyran dyes are trapped within the hydrophobic hybrid matrices synthesized from $\mathrm{MeSi}(\mathrm{OEt})_{3}$. The molecule turns from colourless to coloured upon irradiation and (ii) reverse photochromism is observed in hydrophilic silica synthesized from $\mathrm{Si}\left(\mathrm{OCH}_{3}\right)_{4}$. In this case, the open zwitterionic species form hydrogen bonds with the $\mathrm{Si}-\mathrm{OH}$ groups of the silica matrix. The coloured form is stabilized and can be observed even in the absence of irradiation. Bleaching is obtained upon irradiation in the visible range.

A mixture of both effects however, has been currently observed in most hybrid matrices that contain both hydrophilic and hydrophobic nano-domains. The optical contrast is reduced and thermal fading may be very slow (few hours). Moreover, the gel matrix shrinks upon drying preventing the free rotation of trapped organic molecules and their photochromic properties stop when the gel is dry. Such materials are obviously not of any practical use.

Much better results have been obtained recently by Sanchez using highly hydrophobic sol-gel matrices

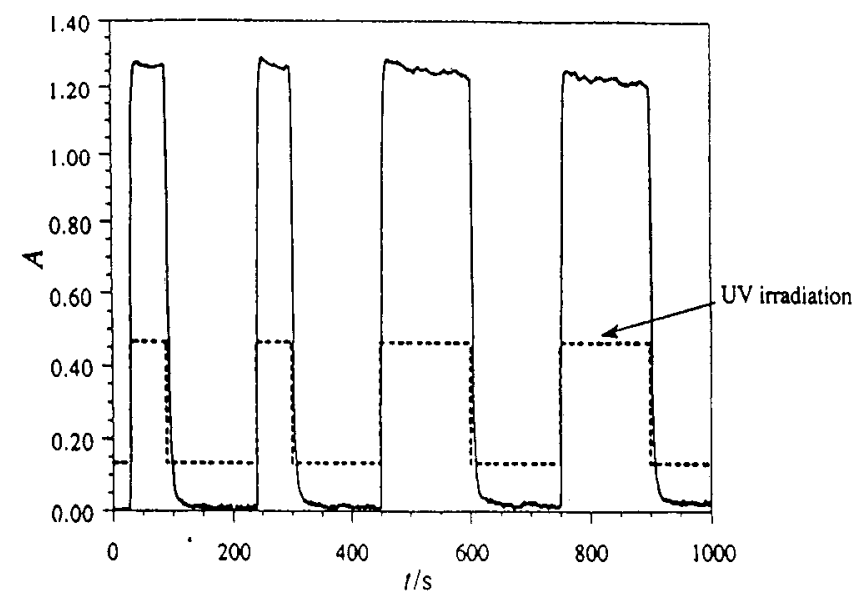

Figure 2. Photochromic response of spiro-oxazine doped in hybrid matrices (DH70/TH30). synthesized via the hydrolysis and co-condensation of $\mathrm{HMeSi}(\mathrm{OEt})_{2}(\mathrm{DH})$ and $\mathrm{HSi}(\mathrm{OEt})_{3}(\mathrm{TH})$. Spirooxazine (SO)-doped matrices exhibit normal photochromism. They are colourless before irradiation. The optical contrast between coloured and bleached states is high $(\Delta O D=1 \cdot 2)$, bleaching is very fast (rate constant $=0.2 \mathrm{~s}^{-1}$ ) and the photochromic behaviour is highly reversible (Schaudel et al 1997) (figure 2). The photochromic response of these SO-doped hybrid materials are to the best of our knowledge much faster than those reported for SO in any other matrix (sol-gel matrices, organic polymers, alcohol solution,...). The high reactivity of $\mathrm{DH} / \mathrm{TH}$ precursors towards hydrolysiscondensation reactions ( $\mathrm{Si}-\mathrm{OH}$ groups are immediately consumed) and the strong hydrophobicity of the resulting matrix are both responsible for the direct and fast photochromic behaviour.

Optical devices require dense matrices that can be perfectly polished, but chemical sensors can be obtained when the organic molecule is embedded within a porous sol-gel matrix. Small analytes then diffuse in and out of the silica matrix and react with entrapped organic dyes. Moreover, fibres, thin films, coatings or planar wave guides can be easily made via the sol-gel process. Optical fibres for chemical sensing have been developed. The first approach developed by MacCraith et al (1997) was to coat an organically-doped sol-gel film at the end of an optical fibre and use evanescent wave excitation to detect changes in the optical spectrum of the embedded dye. More recently, sol-gel optical fibres have been developed, with their diameter being in the range 20-200 $\mu \mathrm{m}$. Doped with fluoresceine, they were shown to be sensitive to ammonia and $\mathrm{HCl}$ vapours, with a response time of 1-2 sec (MacCraith et al 1997).

\section{Bioencapsulation within sol-gel matrices}

It has been shown that enzymes encapsulated within a porous oxide matrix retain their biological activity (Braun et al 1990). They can be used for the realization of biocatalysts and biosensors (Avnir et al 1994; Dave et al 1994; Livage 1996). Glucose oxidase (GOD) is by far the most studied enzyme for applications in the field of medicine and food industry. GOD is capable of catalyzing the oxidation of D-glucose by molecular oxygen into $\mathrm{D}$-gluconolactone and $\mathrm{D}$-gluconic acid: $\mathrm{C}_{6} \mathrm{H}_{12} \mathrm{O}_{6}+\mathrm{O}_{2} \Rightarrow \mathrm{C}_{6} \mathrm{H}_{10} \mathrm{O}_{6}+\mathrm{H}_{2} \mathrm{O}_{2}$.

The formation of hydrogen peroxide can be followed by optical measurements using another enzymatic reaction in which the oxidation of an organic dye is catalyzed by a peroxidase, such as the horseradish peroxidase (HRP). Both reactions have been performed in the sol-gel glass doped with the enzymes (GOD and HRP) and the dye. The entire glass becomes coloured when dipped into a glucose solution, showing that the enzymatic 


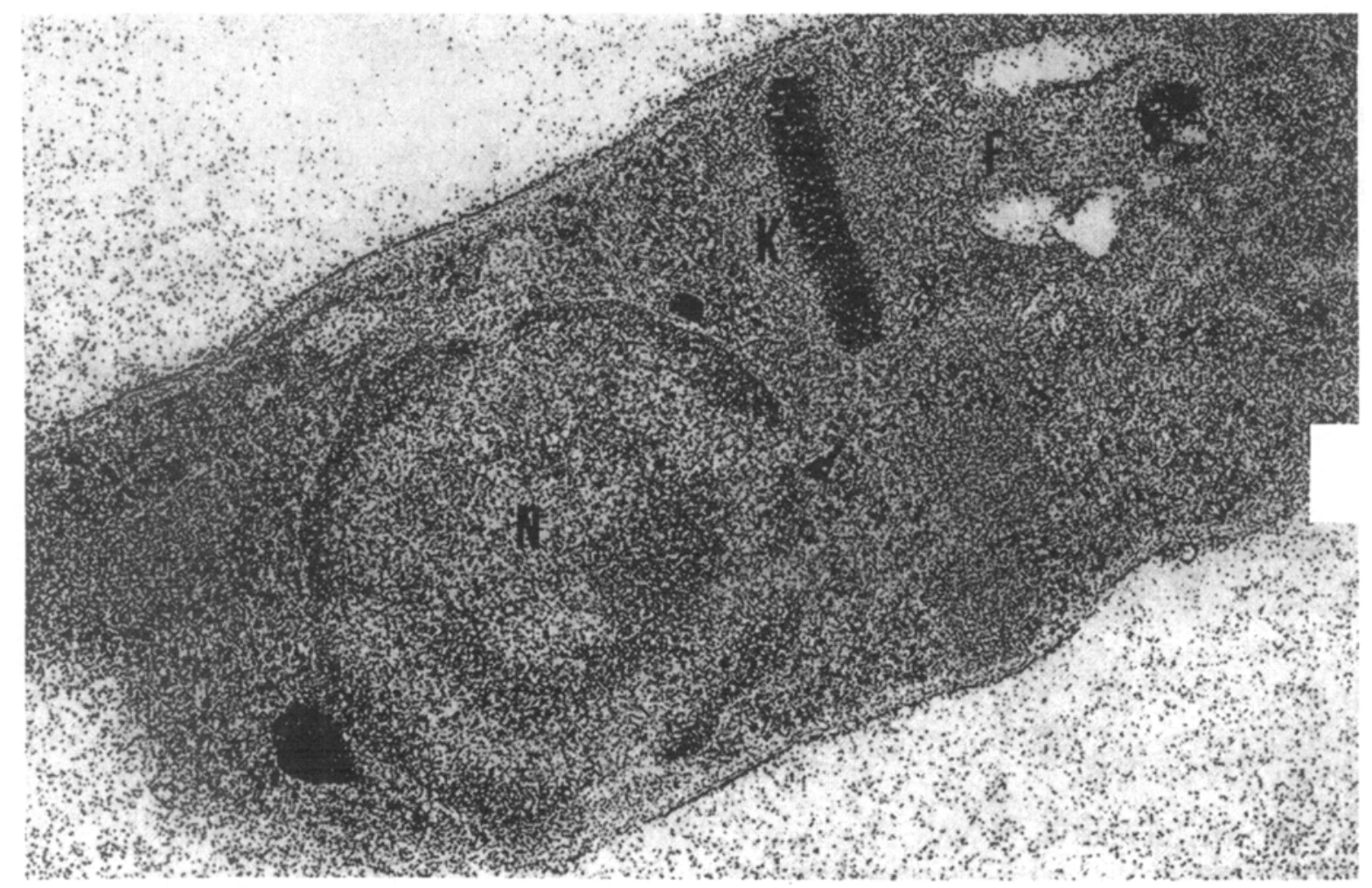

\section{$0.5 \mu \mathrm{m}$}

Figure 3. Transmission electron microscopy of a Leishmania donovani infantum cell in a sol-gel matrix, showing that the cellular organization is preserved after encapsulation.

activity is distributed throughout the gel and that the colour change is not due to surface reactions only (Yamanaka et al 1992).

The presence of glucose in the solution can also be detected via electrochemical means by following the redox reactions at the active site of GOD. However because of the steric hindrance of the protein molecule, a ferrocene mediator has to be used in order to transfer electrons from the hidden active site to the electrode. Faradaic current is then proportional to the amount of converted glucose (Audebert et al 1993). Bio-sensors based on silica-GOD films coated onto an oxygen electrode have also been made. These are highly sensitive as oxygen depletion at the electrode is used to measure the amount of converted glucose (Tatsu et al 1992).

Antigen-antibody reactions have been carried out within sol-gel matrices, extending the field of sol-gel chemistry towards immunosensors (Livage et al 1996). However, antibodies are large biomolecules that can hardly diffuse through the pores of a sol-gel matrix. Therefore, most immunoassays have been carried out with antibodies that are either bonded at the surface or trapped within the sol-gel matrix. Specific haptens are then used. They are much smaller and can diffuse easily through the pores of the sol-gel matrix. These reactions have been developed for the biodetection of chemicals such as atrazine: the most widely used herbicide. Antiatrazine antibodies are trapped within the sol-gel matrix and nanograms of atrazine are applied on to $\mathrm{SiO}_{2}$ sol-gel columns doped with this antibody. Titration of eluted solutions shows that high amounts of atrazine remain bound to antiatrazine antibodies inside the silica gel (Turniansky et al 1996).

For medical applications, the cells of parasitic protozoa (Leishmania donovani infantum) have been trapped within the sol-gel matrices and used as antigens for blood tests with human sera (Barreau et al 1994). Transmission electron microscopy shows that the cellular organization of the parasites is well preserved and that the plasma membrane is unaltered (figure 3 ). This is very important as antigenic determinants are situated at the outside surface of the membrane.

Antigen-antibody interactions were followed by the so-called enzyme linked immunosorbent assays (ELISA) which is now widely used in parasitology. Encapsulation is performed directly within the 96 wells of a microtitre plate and human sera to be analyzed are poured onto 


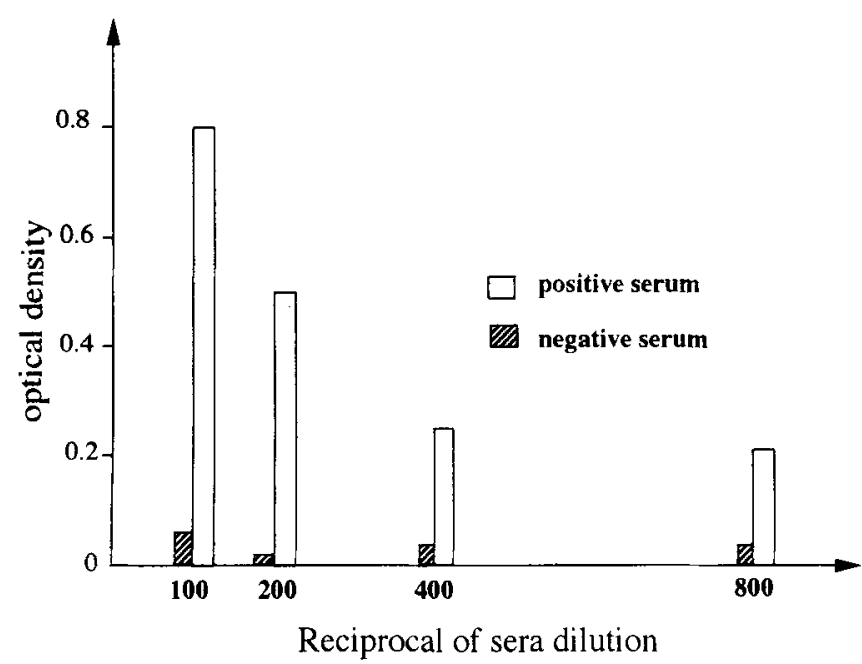

Figure 4. Optical density measurements of ELISA assays performed with $L$. donovani infantum cells encapsulated within a silica gel.

the doped silica gel. Antigen-antibody associations are detected via enzyme conjugates with horseradish peroxidase, which after binding to the antibody-antigen complex give a coloured reaction in the presence of orthophenyldiamine and $\mathrm{H}_{2} \mathrm{O}_{2}$. Optical density measurements show a clear-cut difference between negative and positive sera (figure 4). The optical density of positive tests decreases regularly with sera dilution, showing that Leishmania cells have not been leached out by washing. Large immunoglobulins can diffuse through the mesopores of the sol-gel matrix and bind specifically to the membrane epitopes.

Mammalian tissues such as the pancreatic islets of Langerhans are known to produce insulin in response to glucose challenge. After encapsulation they have been transplanted into a diabetic mouse where they retain their activity. The fine porosity of the gel though protects transplanted islets against antibody aggression, but it permits nutrients to reach the cell and the byproducts to escape. Urinary excretion of glucose dropped to almost zero within a few days of transplantation and remained close to zero for almost 3 months. In addition, both blood sugar and blood insulin concentrations were normal. After one month of transplantation, the surgically-removed transplant showed no evidence of fibrosis. Such transplants, if viable for extended lengths of time, could emerge as a viable treatment for diabetes (Pope et al 1995; Carturan et al 1997).

\section{Conclusion}

The sol-gel process offers many potential advantages compared to the usual solid-state reactions. Solution chemistry in which weak interactions favour the selfassembling of molecular precursors opens new possibili- ties for the synthesis of multicomponent ceramics. Alkoxide precursors can be chemically modified by complexation. Condensation reactions can then be controlled giving monodispersed oxide nanoparticles. Sol-gel chemistry also allows the synthesis of hybrid organicinorganic materials with improved properties. Such materials will find applications in the field of sol-gel optics for the realization of optical devices and sensors. Even biomolecules and microorganisms can be encapsulated within the sol-gel matrices. This emerging field could lead to new nanocomposites in which fragile organic or biological species are mixed with hard oxide matrices.

\section{References}

Audebert P, Demaille C and Sanchez C 1993 Chem. Mater. 5 911

Avnir D, Braun S, Lev O and Ottolenghi M 1994 Chem. Mater. 61605

Barreau J Y, Da Costa J M, Desportes I, Livage J, Monjour L and Gentilini M 1994 C.R. Acad. Sci. Paris 317653

Blanchard J, Barboux-Doeuff S, Maquet J and Sanchez C 1995 New J. Chem. 19929

Boilot J P, Chaput F, Gacoin T, Malier L, Canva M, Brun A, Lévy Y and Galaup J P 1996 C.R. Acad. Sci. Paris 32227

Braun S, Rappoport S, Zusman R, Avnir D and Ottolenghi M 1990 Mater. Lett. 101

Carturan G, Dellagiacoma G, Rossi M, Dal Monte R and Muraca M 1997 Sol Gel Opt. SPIE 3136366

Chatry M, Henry, In M, Sanchez C and Livage J 1994 J. Sol-Gel Sci. Tech. 1233

Dave C, Dunn B, Valentine J S and Zink J I 1994 Anal. Chem. 66 A 1120

Guizard C, Julbe A, Larbot A and Cot L 1994 in Chemical processing of ceramics (eds) B I Lee and E J A Pope (New York: Marcel Dekker Pub.) p. 501

Levy D 1997 Chem. Mater. 92666

Livage J 1996 C.R. Acad. Sci. Paris 322417

Livage J, Henry M and Sanchez C 1988 Prog. Solid State Chem. 18259

Livage J, Roux C, Da Costa J M, Desportes I and Quinson J F 1996 J. Sol-Gel Sci. Tech. 745

MacCraith B D, McDonald C M C, McEvoy A K, Butler T, O'Keeffe G and Murphy V 1997 J. Sol-Gel Sci. Tech. 81053

Pope E J A, Braun K, van Hirtum M, Peterson C M, Tresco $\mathrm{P}$ and Andrade J D 1995 Ceram. Trans. 5533

Sanchez C and Ribot F 1994 New J. Chem. 181007

Sanchez C, In M, Toledano P and Griesmar P 1992 Mater. Res. Soc. Symp. Proc. 271669

Schaudel B, Guermeur C, Sanchez C, Nakatani K and Delaire 1997 J. Mater. Chem. 761

Scolan E and Sanchez C 1998 Chem. Mater. 103217

Tatsu Y T, Yamashita K, Yamaguchi M, Yamamura S, Yamùamoto $\mathrm{H}$ and Yoshikawa S 1992 Chem. Lett. 1615

Yamanaka S A, Nishida F, Ellerby L M, Nishida C R, Dunn B, Valentine J S and Zink J I 1992 Chem. Mater. 4495

Turmiansky A, Avnir D, Bronshtein A, Aharonson $\mathrm{N}$ and Altstein M 1996 J. Sol-Gel Sci. Tech. 745 